\title{
Development of band ratioing algorithms and neural networks to detection of oil spills using Landsat ETM+ data
}

\author{
Alireza Taravat ${ }^{*}$ and Fabio Del Frate
}

\begin{abstract}
Accurate knowledge of the spatial extents and distributions of an oil spill is very impor-tant for efficient response. This is because most petroleum products spread rapidly on the water surface when released into the ocean, with the majority of the affected area becoming covered by very thin sheets. This article presents a study for examining the feasibility of Landsat ETM+ images in order to detect oil spills pollutions. The Landsat ETM+ images for $1^{\text {st }}$, $10^{\text {th }}, 17^{\text {th }}$ May 2010 were used to study the oil spill in Gulf of Mexico. In this article, an attempt has been made to perform ratio operations to enhance the feature. The study concluded that the bands difference between 660 and $560 \mathrm{~nm}$, division at 660 and 560 and division at 825 and $560 \mathrm{~nm}$, normalized by $480 \mathrm{~nm}$ provide the best result. Multilayer perceptron neural network classifier is used in order to perform a pixel-based supervised classification. The result indicates the potential of Landsat ETM+ data in oil spill detection. The promising results achieved encourage a further analysis of the potential of the optical oil spill detection approach.
\end{abstract}

Keywords: oil spills, multi-spectral, Landsat ETM+, neural networks, remote sensing

\section{Introduction}

Oil spills are causing serious damage to marine and coastal ecosystem. It is estimated that $0.25 \%$ of world oil production ends up in the ocean. However, the main contribution of oil pollution originating from transportation activities still originates not from ship accidents, but from routine ship operations like tank washing and engine effluent discharges [1]. Timely and accurate detection of oil slicks help to monitor oil spills and manage coastal resources. The detection of oil spills can efficiently be improved by the use of satellite images which are characterized by suitable special resolution for this purpose [2]. Remote sensing techniques include radar, microwave, infrared, and visible sensors [3]. However, most of oil spills are estimated by Synthetic Aperture Radar (SAR) data [3], which are limited by revisit frequency and coverage.

The exploitation of optical satellite images allows for large areas monitoring and remote zones control, providing more frequent information if compared to the use of SAR images only. Moreover, the possibility of detecting oil

\footnotetext{
* Correspondence: art23130@gmail.com

* Correspondence: art23130@gmail.com
Information, Systems and Production Department, Tor Vergata University, 00133 Rome, Italy
}

spills by optical satellite sensors has been demonstrated [4-6].

It is the optical properties and chemistry $(\mathrm{OH}, \mathrm{CN}$, and $\mathrm{CH}$ bonds) of oil that makes it detectable by remote sensing techniques in marine environment [1].

From an optical perspective, the effect of an oil layer on water can be described by two main processes:

(1) The specular reflection of light off the surface of the oil layer, and more importantly

(2) The absorption of up-welling light from the water column by the overlying oil layer $[5,7]$.

The contrast of sea areas polluted by oil depends on the form of the oil substance. It is negative, positive, or zero with film, and only positive with suspensions [5].

In the visible region of the electromagnetic spectrum, oil has a higher surface reflectance than water [8]. So, reliable identification of oil spill by remote sensing is only possible if the difference in measured radiance between an oil covered and a clean surface is greater than the background variability. 
In the literature, the two main methods of statistical and neural network-based classification have been proposed for detecting oil spills. Solberg et al. and Topouzelis et al. [9-11] detected oil slicks from SAR images by combining a statistical model with a rule-based approach. Del Frate et al. [12] detected oil spills based on a multilayer perceptron (MLP) neural network using ERS images. However, to the best of the authors' knowledge, automatic oil spill detection by neural networks in optical data is not reported in the literature. We observe that in the case of optical data, where a spectral signature for each pixel is available, a pixel-based algorithm can be designed. This is not possible with SAR where the detection is usually implemented starting from a single-band acquisition. This means that a preliminary image segmentation is necessary to extract the dark spot and an object classification to distinguish between actual oil spill and look-alikes is then applied.

In this article, an attempt has been made to perform ratio operations to enhance the oil spots, extracting the features by an MLP neural network, and demonstrate the potential of Landsat ETM+ data in oil spill monitoring in the Gulf of Mexico based on the optical properties of oil slicks detected by neural network.

\section{Methods}

Landsat ETM+ images for the area from $29 \mathrm{~N}$ to $27 \mathrm{~N}$ and $87 \mathrm{~W}$ to $90 \mathrm{~W}$ for Gulf of Mexico, acquired in $1^{\text {st }}, 10^{\text {th }}$, and $17^{\text {th }}$ May 2010 were used to study the previously known oil spills [13]. Landsat ETM+ has eight bands which may be combined in various ways by assigning one band to each of the three visible channels: red, green, and blue, to create a false color image.

Subimages containing oil spills were extracted using the Area of Interest tool of ENVI (Environment for Visualizing Images) software to spare disk space and to make classification and image interpretation more expedient and focused.

The data were then projected in Geo (lat/long) projection and WGS84 datum. Further the image was exported into *.TIFF format for further analysis (slick detection, feature extraction, spectral enhancement, and filtering).

The stripes in Landsat ETM+ data (caused by the Scan Line Corrector in the ETM+ instrument failed On May 31, 2003) have been removed by a developed model which identifies stripe positions based on edgedetection and applies line-tracing algorithms. Pixels not affected by striping are used to construct spline functions describing spatial gray level distributions of an image. Detected stripes are corrected by replacing the pixels with more reasonable gray values computed from constructed spline functions.

To produce optimal contrast and variation for color composition of those individual bands, ratio operations were applied to the images with various band combinations. For the classification test, MLPs have been considered, which have been found to have the best suited topology for pixel level classifications [14].

These are feedforward networks, where the input flows only in one direction to the output, and each neuron of a layer is connected to all neurons of the successive layer but has no feedback to neurons in the previous layers

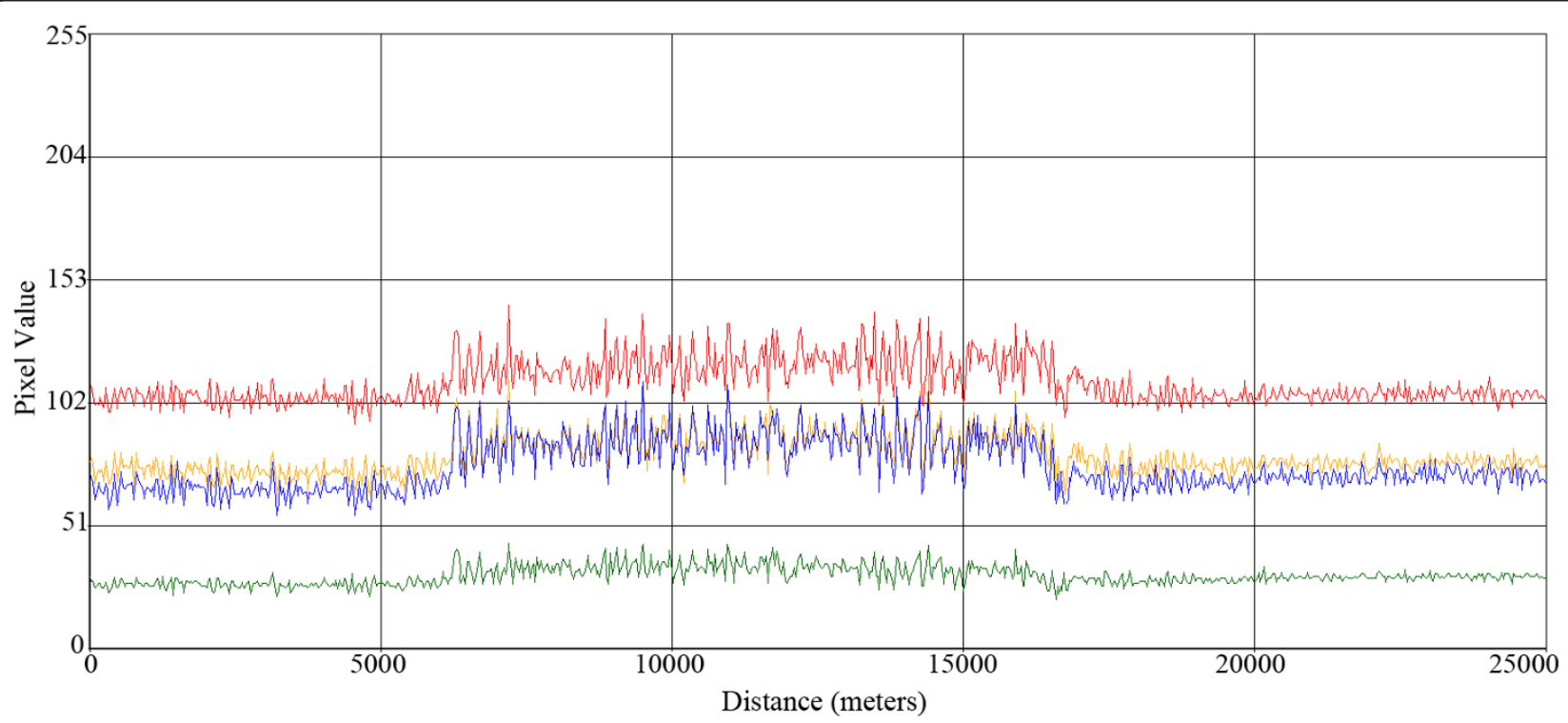

Figure 1 Profile along transect A ( $1^{\text {st }}$ May 2010, Original Image) 
[14]. The individual neuron is the elemental building block of each layer, and it is mainly characterized by its activation function. An activation function, $\phi(v)$, defines the output of a neuron in terms of the linear combination of inputs, v. There are different kinds of activation functions: the threshold function, the piecewise-linear function, and the sigmoid function [14]. The most commonly used is the sigmoid function. An example of the sigmoid function is the logistic function, defined by Equation (2) where $a>0$ is the slope parameter;

$$
\phi(\mathrm{V})=\frac{1}{\left(1+\mathrm{e}^{-\mathrm{av}}\right)}
$$

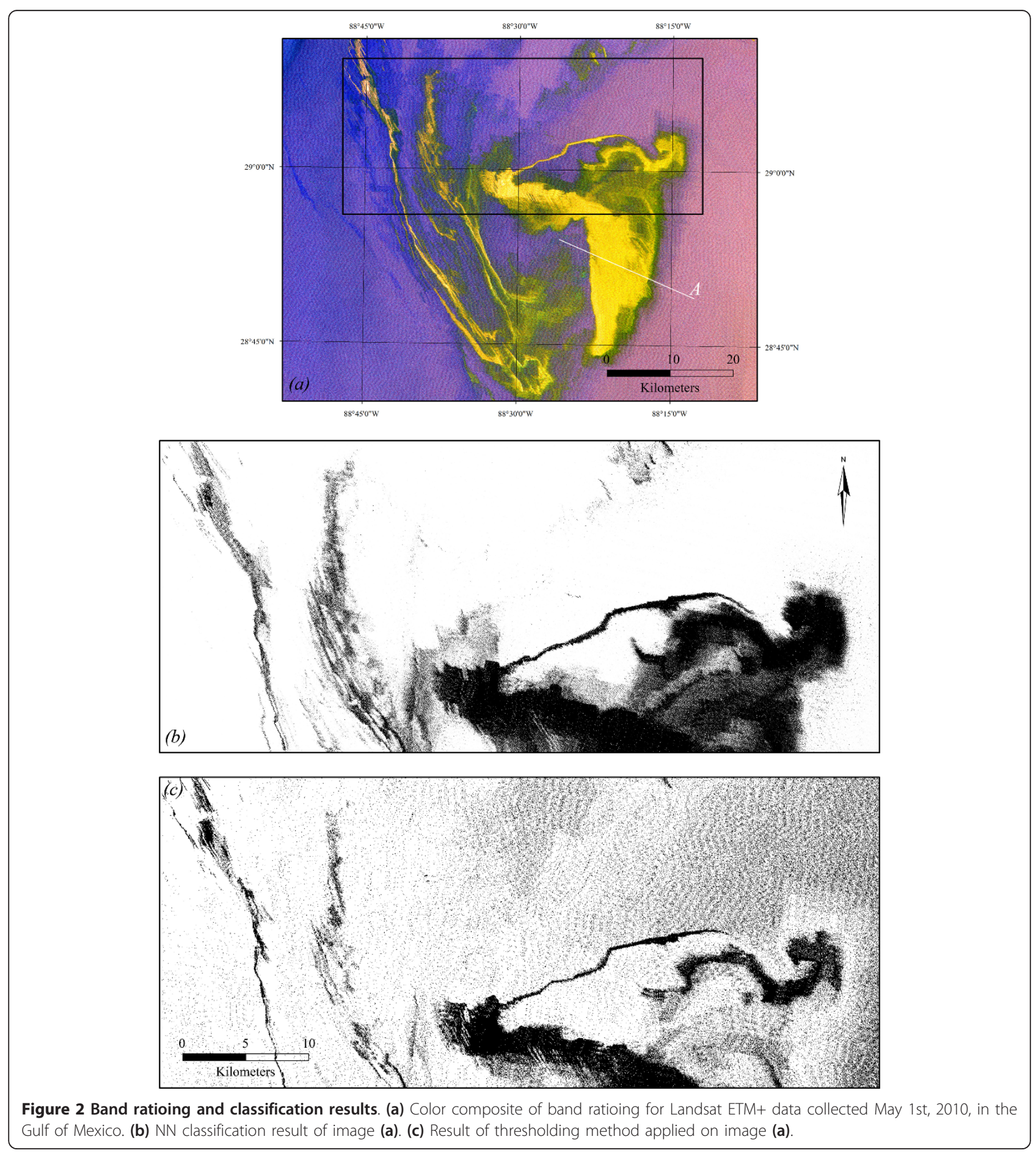


The activation functions defined in Equation. (1) range from 0 to +1 . It is sometimes desirable to have the activation function range from -1 to +1 , in which case the activation function assumes an anti-symmetric form with respect to the origin. For the corresponding form of a sigmoid function, we may use the hyperbolic tangent function, defined by

$$
\mathrm{C}(\mathrm{V})=\tanh (\mathrm{V})
$$

Allowing an activation function of the sigmoid type to assume negative values as prescribed by Equation (2) has analytic benefits [14]. In our study, the use of hyperbolic tangent function provided better results than those obtained with the sigmoid function of Equation (1).

The net was trained using the back propagation algorithm, which uses a gradient search technique and iteratively adjusts the weight coefficients in the network to minimize an error function equal to the mean square difference between the desired and the actual net output [14].

\section{Result and discussion}

The earlier studies carried out by $\mathrm{Hu}$ et al. [6] reported that the shorter wavelengths were more sensitive to optical signature of oil; therefore, Landsat ETM+ data in spectral bands B1 $(480 \mathrm{~nm}), \mathrm{B} 2(560 \mathrm{~nm}), \mathrm{B} 3(660 \mathrm{~nm})$, B4 $(825 \mathrm{~nm})$ have been used in this study [6].

As it is already mentioned, the refractive index of oil is greater than that of sea water, but there are possibilities of masking the data, while performing atmospheric corrections [15]. Therefore, in order to identify the oil spill area, just geometrically corrected data have been used.
To identify the spectral signature of oil spill, a spectral profile along transect $(A)$ was plotted. The visual interpretation in individual bands did not produce significant signature of oil (Figure 1). In order to identify the specific signatures of oil spill by enhancing the contrast, band ratio operations were performed. The ratios were computed using 65 different combinations of bands.

To determine which combination showed the best contrast between the surface slick and surrounding clear ocean water, we extracted data along several transect lines for each band combination [4]. The ratio combinations that showed excellent contrast (about -0.2, defined as $\left(R_{\mathrm{s}}-R_{\mathrm{c}}\right) / R_{\mathrm{c}}$ where " $R_{\mathrm{s}}$ " and " $R_{\mathrm{c}}$ " stand for slick luminance and clear water luminance, whereas the contrast of the original bands are about 0.07 ) and the most significant for retrieving oil spill are given below:

$$
\begin{aligned}
& \mathrm{RS} 1=(\mathrm{B} 4 / \mathrm{B} 2) / \mathrm{B} 1 \\
& \mathrm{RS} 2=(\mathrm{B} 3 / \mathrm{B} 2) / \mathrm{B} 1 \\
& \mathrm{RS} 3=(\mathrm{B} 3 / \mathrm{B} 2) / \mathrm{B} 1
\end{aligned}
$$

These combinations can be interpreted based on spectral signature of oil and water background in landsat ETM+. Oil and water background show steadily increasing reflectance spectrum between wavelength 475-675 $\mathrm{nm}$, while they have different level of absorption in 675$800 \mathrm{~nm}$, thus, information of oil spill could be extracted by band ratio of $\mathrm{B} 4 / \mathrm{B} 2$ and $\mathrm{B} 3 / \mathrm{B} 2$ [8]. There is a decrease in water background reflection from 550-750 $\mathrm{nm}$; so to get some information on background the

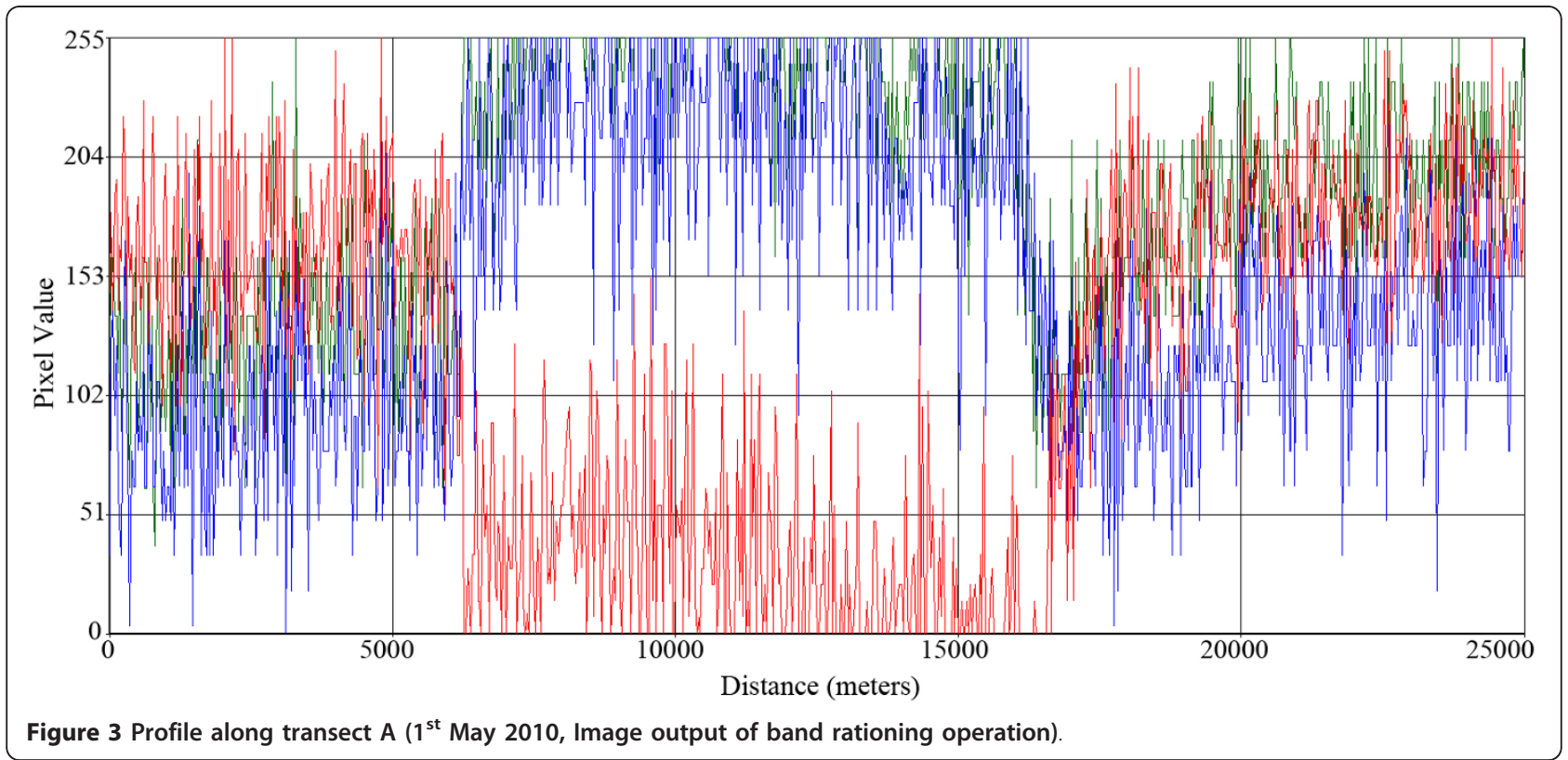


difference of bands 3 and 2 can be applied. Additionally, the difference between bands 3 and 2 is useful to visualize the data in RGB format.
The shorter wavelength at blue (B1) is normally found to be contaminated with the signatures of biogenic materials. Therefore, for removing biogenic materials
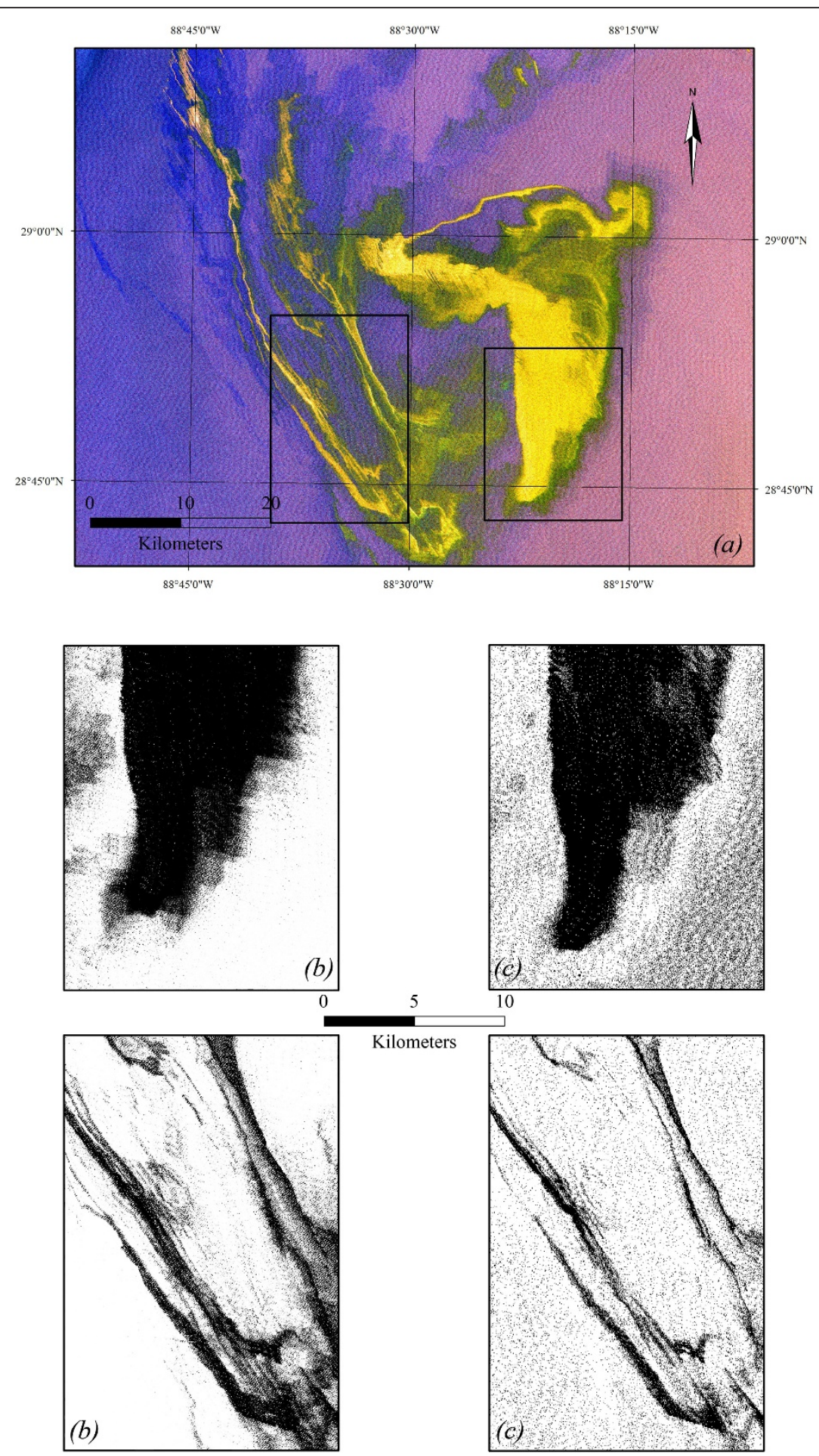

Figure 4 Band ratioing and classification results. (a) Subimages of color composite of band ratioing for Landsat ETM+ data collected May $17^{\text {th }}, 2010$, in the Gulf of Mexico. (b) Subimages of color composite of band ratioing for Landsat ETM+ data collected May 10 ${ }^{\text {th }}, 2010$, in the Gulf of Mexico, used for training the NN. (c) NN classification result of image (a). (d) NN classification result of image (b). 
effects, the results were normalized with respect to 480 nm [15].

Color-composite images can be created by assigning RS1, RS2, and RS3 values, computed from the Landsat ETM+ data into red, green, and blue channels, respectively. The algorithm developed for oil spill was applied for the data of Gulf of Mexico on $1^{\text {st }}, 10^{\text {th }}$, and $17^{\text {th }}$ May 2010.

Figure 2a presents the ratio image of Gulf of Mexico at May $1^{\text {st }}, 2010$. The oil spill signatures were very well identified along transect A (Figure 3).

When thick oil spots are present in clear, deep ocean water, strong yellow and orange tones in the color-composite image are indicative of areas containing them (Figure 2a). These tones result from the relatively higher values of RS1 and RS2 and relatively lower values for RS3 for oil spot as compared to clear, deep ocean water (Figure 3). Blue and purple tones indicate the absence of oil or insufficient quantity or thickness to cause spectral differences associated with oil in spectral bands.

Once the best ratios to discriminate between the pixels contain oil and clear water have been determined, an MLP algorithm for pixel classification has been designed. The result has been compared with the result of Multiband thresholding algorithm which is the combined result of AND operation for thresholded RS1 and RS3 bands.

Several attempts have been made to properly select the number of units to be considered in the hidden layers. The pixels for train/test the net are 80,152 pixels which have been extracted from one image $\left(10^{\text {th }}\right.$ May
2010, Gulf of Mexico) (Figure 4b). The training sets contain $60 \%$ and the test sets contain $40 \%$ of all pixels which are not belonging to the training set. Pixel selection for train/test set has been done randomly and repeated six times; so the presented results of root mean square error (RMSE) errors are the average of these repetitions for each topology (Figure 5). The topology 3-4-2 has been finally chosen for its good performance in terms of classification accuracy, RMSE, and training time. The number of about 10,000 training cycles was sufficient to get the network learned. The described topology is reported in Figure 6. The input of the net consists of RS1, RS2, and RS3 bands and the output providing classified pixels in terms of oil spill or others and one MLP NNs has been used for classifying all images.

Accuracy assessment has been carried out considering the other two images $\left(1^{\text {st }}\right.$ May $2010,17^{\text {th }}$ May 2010). For both of them 5,000 pixels have randomly been selected and then labeling made by visual interpretation. As it has been shown in Table 1, the overall rate of the accurately classified pixels in image collected at $1^{\text {st }}$ May 2010 is $97 \%$, whereas the accuracy of the same image segmented by thresholding method is $43 \%$. Also in the second test image ( $17^{\text {th }}$ May 2010) the performance of the neural classification is satisfactory with an overall accuracy of $95 \%$.

In Figures $2 \mathrm{~b}$ and $7 \mathrm{~b}$, some subareas of image collected at May $1^{\text {st }} 2010$ have been shown, where the better advantage of $\mathrm{NN}$ can clearly be observed based on visual interpretation.

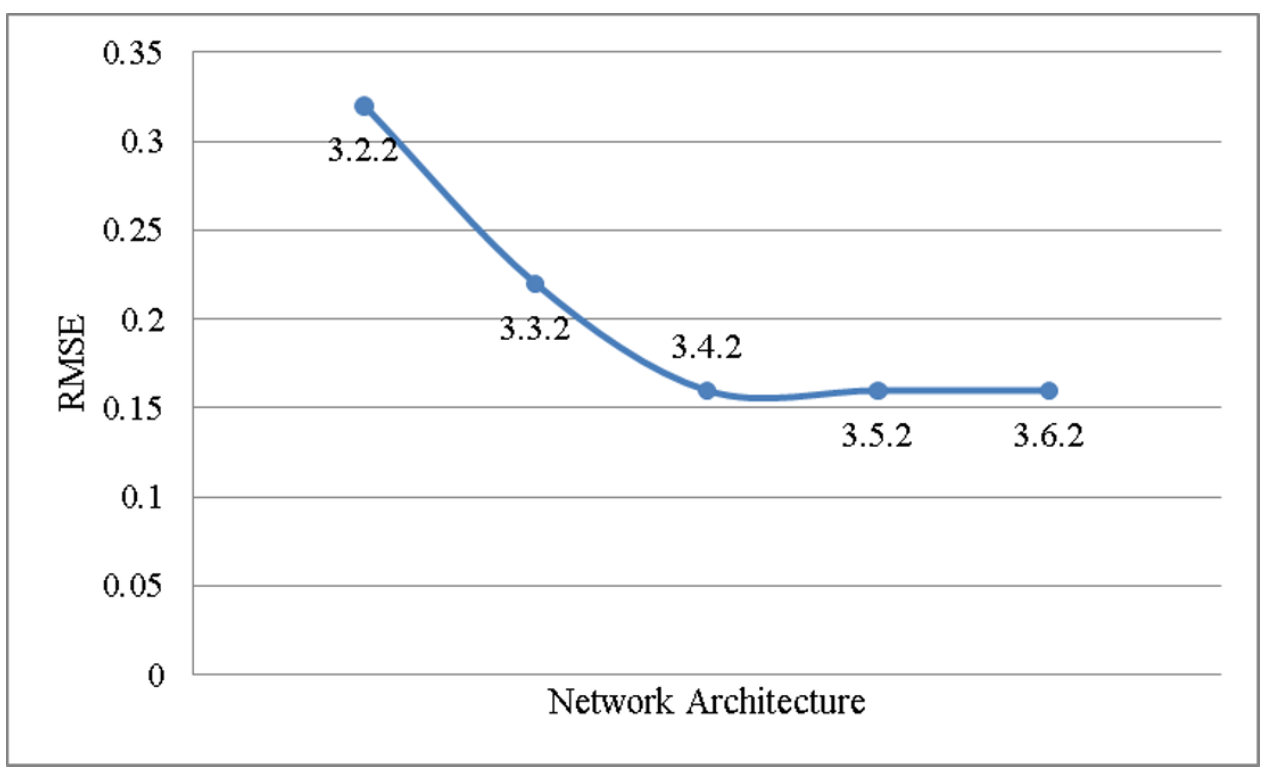

Figure 5 RMSE errors for different NN topologies. 


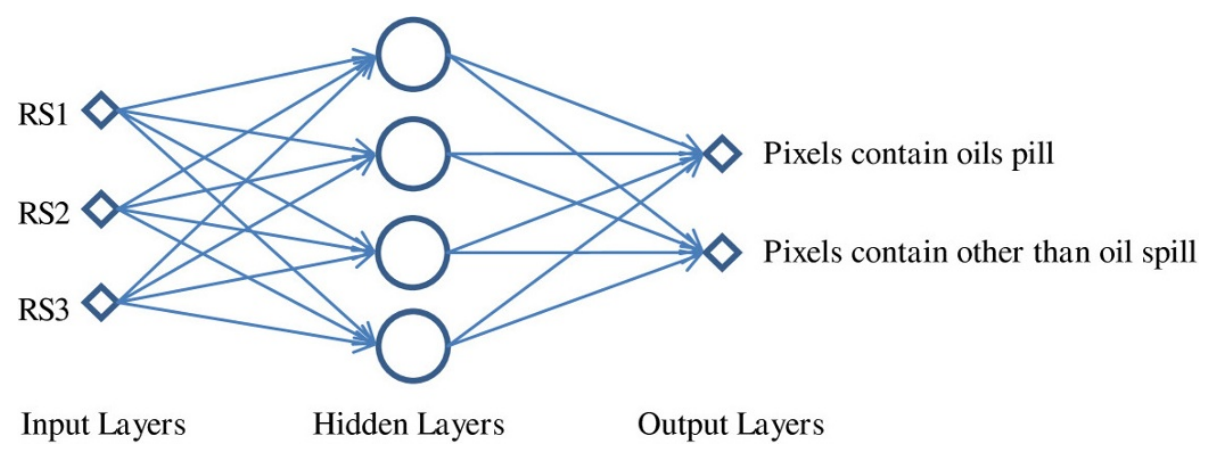

Figure 6 Feedforward topology for an NN.
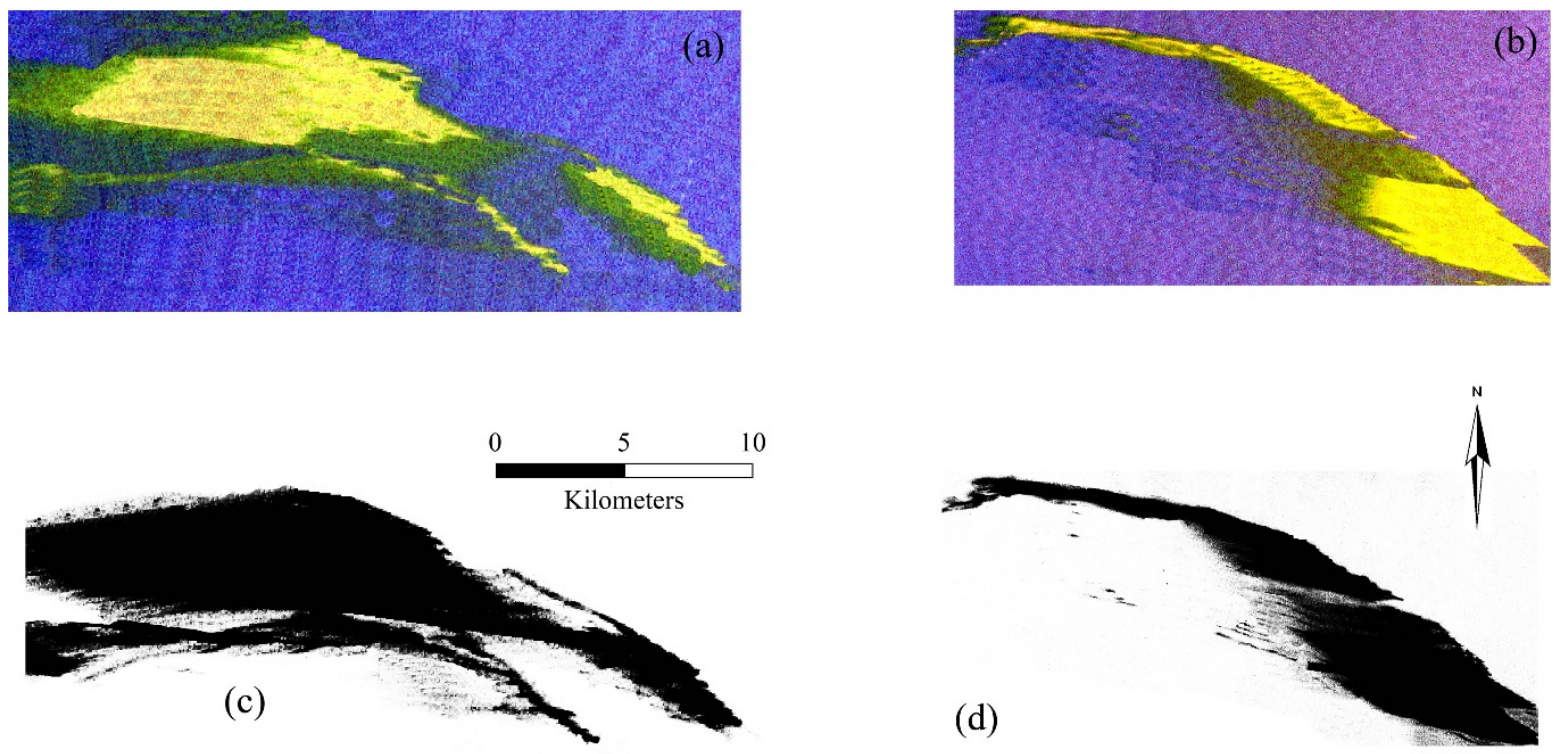

Figure 7 Band ratioing and classification results. (a) Color composite of band ratioing for Landsat ETM+ data collected May $1^{\text {st, }} 2010$, in the Gulf of Mexico. (b) NN classification result of image (a). (c) Result of thresholding method applied on image (a).

Table 1 The error matrix of classified images shows the accuracy assessment

\begin{tabular}{cccc}
\hline Image & Well classified Pixels & Misclassified pixels & Accuracy $\%$ \\
\hline ETM+ $\left(1^{\text {th }}\right.$, May 2010) & 4850 & 150 & $97 \%$ \\
\hline ETM+ $\left(10^{\text {th }}\right.$, May 2010) & 4950 & 50 & $99 \%$ \\
\hline ETM+ $\left(17^{\text {th }}\right.$, May 2010 $)$ & 4750 & 250 & $95 \%$ \\
\hline
\end{tabular}

The neural network simulator (SNNS) developed at the University of Stuttgart, Stuttgart, Germany, has been used for the classification algorithm implementation and proved to be a high level and reliable software package [16].

\section{Conclusion}

This article presents and demonstrates the potential of Landsat ETM+ to automatically detect and extract oil spill in marine environment. The band ratioing approach used in this study was found to work well for the identification of potential hydrocarbon contaminants in water. It has been observed that the bands difference between bands $3(660 \mathrm{~nm})$ and $2(560 \mathrm{~nm})$, division ratio of bands $3(660 \mathrm{~nm})$ and $2(560 \mathrm{~nm})$ and division ratio of bands 4 $(825 \mathrm{~nm})$ and $2(560 \mathrm{~nm})$ normalized by band $1(480 \mathrm{~nm})$ were most suitable to retrieve oil spill.

MLPs with different topologies have been applied to a set of features describing oil spill characteristics in order 
to perform a supervised classification. Best performances are obtained using an MLP neural network with 3:4:2 topology trained by the standard backpropagation algorithm. This algorithm has been designed for Landsat ETM + data but it can be applied on different multispectral data (WorldView2, Spot, etc.).

The largest challenge in detection of oil spills in SAR images is accurate discrimination between oil spills and look-alikes. Natural films cannot always be properly distinguished from oil spills based on a SAR image alone but additional information can be derived from optical sensors. Future oil spill systems should incorporate oil spill information from multisensory studies.

\section{Competing interests}

The authors declare that they have no competing interests.

Received: 11 July 2011 Accepted: 10 May 2012 Published: 10 May 2012

\section{References}

1. BE Ornitz, MA Champ, Oil Spills First Principles:Prevention and Best Response (Elsevier, Amsterdam, 2002), p. 653

2. KA Kvenvolden, CK Cooper, Natural seepage of crude oil into the marine environment. Geo-Marine Lett. 23(3), 140-146 (2003). doi:10.1007/s00367-0030135-0

3. C Brekke, AHS Solberg, Oil spill detection by satellite remote sensing. Remote Sens Environ. 95(1), 1-13 (2005). doi:10.1016/j.rse.2004.11.015

4. C Hu, X Li, WG Pichel, E Muller-Kerger, Detection of natural oil slicks in the NW Gulf of Mexico using MODIS imagery. Geophys Res Lett. 36(1), L01604 (2009)

5. Z Otremba, J Piskozub, Modelling of the optical contrast of an oil film on a sea surface. Opt Exp. 9(8), 411-416 (2001). doi:10.1364/OE.9.000411

6. C Hu., et al, MODIS detects oil spills in Lake Maracaibo, Venezuela. Eos Trans AGU. 84(33), 313-317 (2003)

7. M Wettle., et al, Assessing the effect of hydrocarbon oil type and thickness on a remote sensing signal: a sensitivity study based on the optical properties of two different oil types and the HYMAP and Quickbird sensors. Remote Sens Environ. 113(9), 2000-2010 (2009). doi:10.1016/j.rse.2009.05.010

8. J Svejkovsky, J Muskat, J Mullin, Adding a multispectral aerial system to the oil spill response Arsenal. Sea Technol. 50(8), 17 (2009)

9. AHS Solberg, C Brekke, PO Husoy, Oil spill detection in Radarsat and Envisat SAR images. IEEE Trans Geosci Remote Sens. 45(3), 746-755 (2007)

10. AHS Solberg, ST Dokken, R Solberg, Automatic detection of oil spills in Envisat, Radarsat and ERS SAR images. Geoscience and Remote Sensing Symposium, IGARSS '03. Proceeding. IEEE International (2003)

11. KN Topouzelis, Oil spill detection by SAR images: dark formation detection, feature extraction and classification algorithms. Sensors. 8(10), 6642-6659 (2008). doi:10.3390/s8106642

12. F Del Frate., et al, Neural networks for oil spill detection using ERS-SAR data. IEEE Trans Geosci Remote Sens. 38(5), 2282-2287 (2000). doi:10.1109/36.868885

13. USGS, http://hdds.usgs.gov/hdds/ (2010). HDDS 2010

14. CM Bishop, Neural Networks for Pattern Recognition (Oxford University Press, Oxford, 1995)

15. H Srivastava, T Singh, Assessment and development of algorithms to detection of oil spills using MODIS data. J Indian Soc Remote Sens. 38(1), 161-167 (2010). doi:10.1007/s12524-010-0007-9

16. A Zell., et al, SNNS Stuttgart neural network simulator user manual, (Inst. Parallel Distributed High Performance Syst., Univ. Stuttgart, Stuttgart, Germany, 1995)

doi:10.1186/1687-6180-2012-107

Cite this article as: Taravat and Del Frate: Development of band ratioing algorithms and neural networks to detection of oil spills using Landsat ETM+ data. EURASIP Journal on Advances in Signal Processing 2012 2012:107.

\section{Submit your manuscript to a SpringerOpen ${ }^{\mathcal{O}}$ journal and benefit from:}

- Convenient online submission

- Rigorous peer review

- Immediate publication on acceptance

- Open access: articles freely available online

- High visibility within the field

- Retaining the copyright to your article

Submit your next manuscript at $>$ springeropen.com 